\title{
Prostate Disorder
}

National Cancer Institute

\section{Source}

National Cancer Institute. Prostate Disorder. NCI Thesaurus. Code C26865.

A non-neoplastic or neoplastic disorder that affects the prostate gland. Representative examples include prostatitis, prostatic intraepithelial neoplasia, and carcinoma. 